Article

\title{
Flexible Ultrahigh-Temperature Polymer-Based Dielectrics with High Permittivity for Film Capacitor Applications
}

\author{
Zejun Pu *, Xiaoyi Zheng, Yuhan Tian, Linqing Hu and Jiachun Zhong * \\ College of Materials Science and Engineering, Sichuan University of Science \& Engineering, Zigong 643000, \\ China; a920036252@163.com (X.Z.); m18381306371@163.com (Y.T.); 18381307059@163.com (L.H.) \\ * Correspondence: puzj@suse.edu.cn or puzejunuestc@163.com (Z.P.); zjcjww@aliyun.com (J.Z.); \\ Tel./Fax: +86-0813-5505-620 (Z.P. \& J.Z.)
}

Received: 24 August 2017; Accepted: 2 November 2017; Published: 10 November 2017

\begin{abstract}
In this report, flexible cross-linked polyarylene ether nitrile/functionalized barium titanate $\left(\mathrm{CPEN} / \mathrm{F}-\mathrm{BaTiO}_{3}\right)$ dielectrics films with high permittivitywere prepared and characterized. The effects of both the $\mathrm{F}-\mathrm{BaTiO}_{3}$ and matrix curing on the mechanical, thermal and dielectric properties of the CPEN/F-BaTiO 3 dielectric films were investigated in detail. Compared to pristine $\mathrm{BaTiO}_{3}$, the surface modified $\mathrm{BaTiO}_{3}$ particles effectively improved their dispersibility and interfacial adhesion in the polymer matrix. Moreover, the introduction of $\mathrm{F}-\mathrm{BaTiO}_{3}$ particles enhanced dielectric properties of the composites, with a relatively high permittivity of 15.2 and a quite low loss tangent of 0.022 $(1 \mathrm{kHz})$ when particle contents of $40 \mathrm{wt} \%$ were utilized. In addition, the cyano $(-\mathrm{CN})$ groups of functional layer also can serve as potential sites for cross-linking with polyarylene ether nitrile terminated phthalonitrile (PEN-Ph) matrix and make it transform from thermoplastic to thermosetting. Comparing with the pure PEN-ph film, the latter results indicated that the formation of cross-linked network in the polymer-based system resulted in increased tensile strength by $\sim 67 \%$, improved glass transition temperature $\left(T_{\mathrm{g}}\right)$ by $\sim 190^{\circ} \mathrm{C}$. More importantly, the $\mathrm{CPEN} / \mathrm{F}-\mathrm{BaTiO}_{3}$ composite films filled with $30 \mathrm{wt} \% \mathrm{~F}_{-} \mathrm{BaTiO}_{3}$ particles showed greater energy density by nearly $190 \%$ when compared to pure CPEN film. These findings enable broader applications of PEN-based composites in high-performance electronics and energy storage devices materials used at high temperature.
\end{abstract}

Keywords: polyarylene ether nitrile; surface functionalization; cross-linking; dielectric properties; energy storage capacity

\section{Introduction}

As one of the most promising high-performance polymers, polyarylene ether nitrile (PEN) has attracted extensive attention in recent years owing to its outstanding properties, including excellent mechanical properties, high thermal stability, radiation resistance and chemical inertia $[1,2]$. These characteristics make it a good candidate to be widely used in various fields, including electronics and electrical appliances, automobiles, outer space, etc. Specifically, the possible applications of PEN as dielectric materials have been widely explored [3,4]. Although the abundant existence of strongly polar nitrile groups $(-\mathrm{CN})$ pendant on the side-chain of PEN can promote the dielectric properties of PEN effectively, the low inherent permittivity $(<5)$ and glass transition temperature (under $250{ }^{\circ} \mathrm{C}$ ) of PEN still impede their use for high-k applications in electrical equipment encountered with extremely high temperature [5]. As we all know, it is effective to enhance the dielectric properties by incorporating PEN with a variety of inorganic conductive fillers, including polyaniline [6], carbon nanotubes [7], graphene [8], etc. Although this kind of PEN composites may possess higher permittivity, their intrinsic percolation characteristics resulted in higher dielectric loss and significantly 
lower breakdown strength [9]. Therefore, more attention to achieve synchronous improvement of permittivity and breakdown strength has been focused on fabrication of PEN composite dielectrics.

In recent years, other strategies, such as blending of polymer with high-k ceramic powder, chemical modification and cross-linking, have been widely adopted to obtain the high-performance PEN composite dielectrics. Tang et al. [10] fabricated core-shell structured $\mathrm{BaTiO}_{3} @$ polymer $\left(\mathrm{F}-\mathrm{BaTiO}_{3}\right)$ nanoparticles through chemical grafting carboxyl-functionalized polyarylene ether nitrile $(\mathrm{PEN}-\mathrm{COOH})$ as the coating layer, and the obtained $\mathrm{F}-\mathrm{BaTiO}_{3} / \mathrm{PEN}$ nanocomposites containing $40 \mathrm{wt} \% \mathrm{~F}_{-} \mathrm{BaTiO}_{3}$ loading content possess a dielectric constant of 13 and loss tangent of 0.023 . Xie et al. [11] reported the fabrication of stretchable PVDF-based composite films by using surface modification of $\mathrm{BaTiO}_{3}$ as fillers and cross-linked PVDF as the polymer matrix, and the mechanical properties and energy storage capacities of the obtained c-PVDF/PDA@BaTiO 3 were obviously improved when compared to pristineBaTiO $\mathrm{B}_{3}$ filled PVDF composites. Yang et al. [12] grafted 4-nitrophthalonitrile onto the ends of PEN polymer chains, and then prepared polyarylene ether nitrile terminated phthalonitrile (PEN-Ph) film combined with post curing at high temperature. Through post curing treatment, the cross-linked PEN film possesses excellent mechanical properties and ultrahigh glass transition temperature up to $380{ }^{\circ} \mathrm{C}$. These researches revealed that introducing cross-links and ferroelectric ceramic particles with high-k into PEN matrix would dramatically improve their comprehensive performance.

As a typical dielectric ceramic, barium titanate $\left(\mathrm{BaTiO}_{3}\right)$ is used extensively to fabricate polymer/ceramic composite dielectrics due to its superior dielectric constants $\left(\varepsilon>10^{3}\right)$ and low loss tangent [13-17]. However, poor dispersion and interfacial adhesion of $\mathrm{BaTiO}_{3}$ particles cause them to become easily agglomerated. In addition, as the fillers content is increased to a high level, e.g., $50 \mathrm{vol} \%$, the uneven electrical field distribution and deteriorated flexibility would have negative influences on the dielectric properties and breakdown strength of the polymer/ceramic composites. In the previous studies, carboxyl-functionalized polyarylene ether nitrile (PEN-COOH), a thermoplastic polymer with a large number of carboxyl groups $(-\mathrm{COOH})$, was employed to coat shielding layer on $\mathrm{BaTiO}_{3}$ particles surface [18]. Consequently, the modified $\mathrm{BaTiO}_{3}$ particles effectively improved their compatibility and dispersibility in the polymer matrix. In addition, to obtain high performance PEN-Ph cross-linked films, PEN-ph is synthesized according to the previously reported method [19]. Through simply post-curing at high temperature, the thermal stability of PEN-ph composites can be improved by a large margin. Therefore, by combining their respective advantages of surface modified $\mathrm{BaTiO}_{3}$ particles and cross-linkable PEN-ph, a kind of polymer/ceramic composite dielectrics could be expected.

In this work, we report the fabrication of flexible cross-linked polyarylene ether nitrile/functionalized $\mathrm{BaTiO}_{3} \quad\left(\mathrm{CPEN} / \mathrm{F}-\mathrm{BaTiO}_{3}\right)$ composite films with high permittivity. $\mathrm{BaTiO}_{3}$ particles were first chemically modified with $\mathrm{PEN}-\mathrm{COOH}$ to form the shielding layers on their surface. To obtain composites with enhanced dispersibility and interfacial adhesion between two phases, the mixed solutionofF- $\mathrm{BaTiO}_{3}$ and $\mathrm{PEN}-\mathrm{ph}$ were precipitated in the as-prepared solution $\left(V_{\mathrm{DIW}} / V_{\mathrm{NMP}}=1: 1\right)$ by using a high-speed shear dispersing machine to obtain homogeneously dispersed powder. Then, the $\mathrm{PEN}-\mathrm{ph} / \mathrm{F}-\mathrm{BaTiO}_{3}$ dielectrics films were prepared by using $\mathrm{F}-\mathrm{BaTiO}_{3}$ particles as fillers and PEN-ph as polymer matrix under melt processing. After further chemical cross-linking at high temperature, the flexible $\mathrm{CPEN} / \mathrm{F}-\mathrm{BaTiO}_{3}$ composite films were successfully fabricated. The combined influence of $\mathrm{F}^{-\mathrm{BaTiO}_{3}}$ and chemical cross-linking on the properties of $\mathrm{CPEN} / \mathrm{F}-\mathrm{BaTiO}_{3}$ composite films were investigated in detail.

\section{Experimental Section}

\subsection{Materials}

Barium titanate $\left(\mathrm{BaTiO}_{3}\right)$ (the diameter: $80 \pm 10 \mathrm{~nm}$; purity: 99.9\%) was purchased from Shanghai Aladdin biochemical technology Co. Ltd., Shanghai, China. In addition, 2,6-dichlorobenzonitrile (DCBN) was purchased from Yangzhou tianchen fine chemical Co. Ltd., Yangzhou, China. 
Hydroquinone (HQ), biphenyl (BP) and potassium carbonate $\left(\mathrm{K}_{2} \mathrm{CO}_{3}\right)$ were purchased from Kelong reagent Co. Ltd., Chengdu, China. All the materials were used without further purification. The structures of carboxyl-functionalized polyarylene ether nitrile ( $\mathrm{PEN}-\mathrm{COOH})$ and polyarylene ether nitrile terminated with phthalonitrile (PEN-ph) are shown in Figure 1. PEN-COOH was synthesized in our laboratory according to the previously reported method [20]. PEN-ph was synthesized by the nucleophilic aromatic substitution polymerization of 2,6-dichlorobenzonitrile (DCBN), hydroquinone (HQ) and biphenyl (BP), followed by termination with 4-nitrophthalonitrile [21]. Then, PEN-ph product was purified several times by acetone and deionized water until impurities were washed out. The number average molecular weight of as-synthesized PEN-COOH and PEN-ph copolymer determined by GPC is $6 \times 10^{3}$ and $3.4 \times 10^{4}$, respectively.
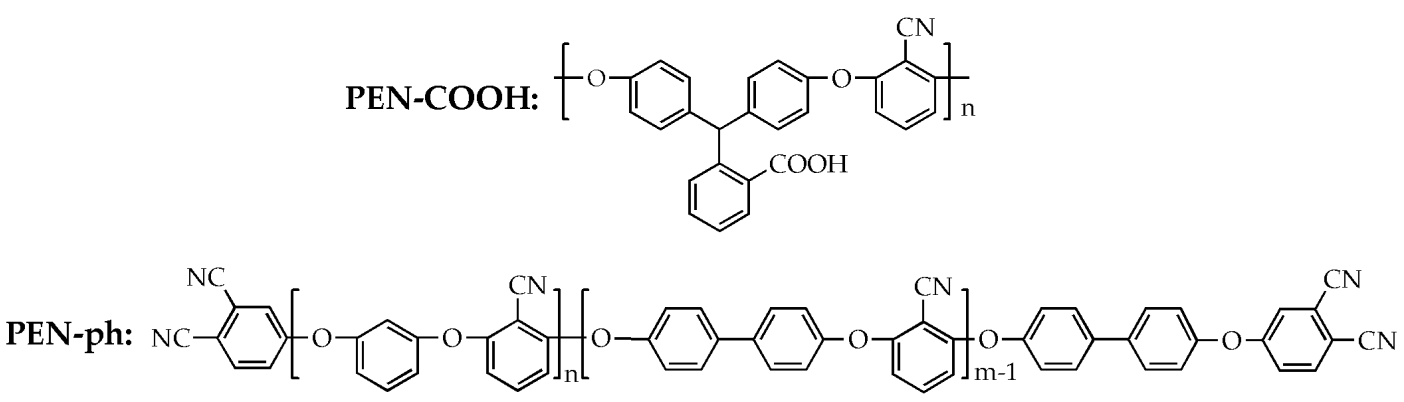

Figure 1. The structures of carboxyl-functionalized polyarylene ether nitrile (PEN-COOH) and polyarylene ether nitrile terminated with phthalonitrile (PEN-ph).

\subsection{Preparation of $\mathrm{F}_{-} \mathrm{BaTiO}_{3}$ Particles}

In this study, the $\mathrm{BaTiO}_{3}$ particles were surface modified using a carboxyl-functionalized polyarylene ether nitrile ( $\mathrm{PEN}-\mathrm{COOH})$ as the surface-grafting agent. $\mathrm{PEN}-\mathrm{COOH}$, a thermoplastic polymer with a large number of carboxyl groups $(-\mathrm{COOH})$, was employed due to its powerful ability to coat different thickness of polymer layers on nearly any oxide particles surface, such as $\mathrm{SiO}_{2}, \mathrm{TiO}_{2}$, $\mathrm{Fe}_{3} \mathrm{O}_{4}$, etc. This kind of strategy has already been verified its high-efficiency in improving dispersibility and compatibility of oxide particles with polymer matrix [18].

\subsection{Preparation of the $\mathrm{CPEN} / \mathrm{F}-\mathrm{BaTiO}_{3}$ Composites Films}

The flexible cross-linked polyarylene ether nitrile/functionalized $\mathrm{BaTiO}_{3}\left(\mathrm{CPEN} / \mathrm{F}-\mathrm{BaTiO}_{3}\right)$ composite films with high permittivitywere fabricated and illustrated in Figure 2. Firstly, the mixed solution of $\mathrm{F}_{-\mathrm{BaTiO}}$ and $\mathrm{PEN}$-ph were precipitated in the as-prepared solution $\left(V_{\mathrm{DIW}} / V_{\mathrm{NMP}}=1: 1\right)$ by a high-speed shear dispersing machine to obtain homogeneously dispersed powder. Then, the $\mathrm{CPEN} / \mathrm{F}-\mathrm{BaTiO}_{3}$ composite films with the thickness of $\sim 60 \mu \mathrm{m}$ were fabricated by melt processing of as-prepared powder combined with post curing at high temperature $\left(260^{\circ} \mathrm{C}, 280^{\circ} \mathrm{C}, 300{ }^{\circ} \mathrm{C}, 320^{\circ} \mathrm{C}\right.$, $340{ }^{\circ} \mathrm{C}$ and $360^{\circ} \mathrm{C}$ every for $3 \mathrm{~h}$ ). The weight contents of $\mathrm{F}-\mathrm{BaTiO}_{3}$ particles, $0,10,20,30$ and $40 \mathrm{wt} \%$, was designed in resultant films and labeled as P-0, P-1, P-2, P-3 and P-4, respectively. Through post curing with high temperature, the phthalonitriles capped at the ends of PEN and the cyano $(-\mathrm{CN})$ groups grafted on the surface of $\mathrm{BaTiO}_{3}$ might form phthalocyanines or triazine ring as the cross-linking points in the system $[22,23]$. Therefore, the obtained cross-linking network would be of great advantage to enhance the thermal stability of the as-prepared composite films. 


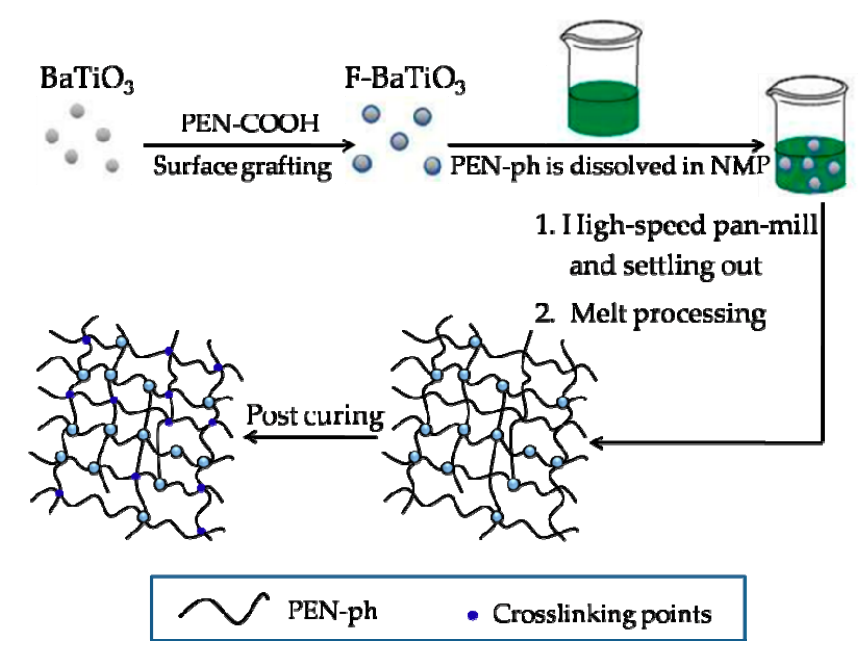

Figure 2. Schematic illustration for the surface modification of $\mathrm{BaTiO}_{3}$ particles and preparation of $\mathrm{CPEN} / \mathrm{F}-\mathrm{BaTiO}_{3}$ composite films.

\subsection{Characterization}

The chemical composition of the samples was characterized by Fourier transform infrared spectra (FTIR, Shimadzu 8000S, Kyoto, Japan). The micro-morphologies of $\mathrm{F}^{-\mathrm{BaTiO}_{3}}$ particles and CPEN/F-BaTiO 3 composite films were observed by transmission electron microscope (TEM, FEI Tecnai G2 F20, Hillsboro, OR, USA) and scanning electron microscope (SEM, FEI INSPECT F50, Hillsboro, OR, USA). The crystal structures of pristine $\mathrm{BaTiO}_{3}$ and $\mathrm{F}-\mathrm{BaTiO}_{3}$ were characterized by $\mathrm{X}$-ray diffraction (XRD, Rigaku, Tokyo, Japan, RINI2400 with $\mathrm{Cu} \mathrm{K} \alpha$ radiation). Mechanical properties of the composite films were performed using a SANS CMT6104 series desktop electromechanical universal testing machine (Shenzhen Sans Materials Testing Machine Co., Shenzhen, China), and the stretching speed was $5 \mathrm{~mm} / \mathrm{min}$. All samples (with the sample size as $10 \times 100 \mathrm{~mm}$ ) were tested at room temperature and reported as an average value for every five samples. Dynamic mechanical analysis (DMA) was carried out on TA instrument (TA-Q800, TA Instruments Ltd., New Castle, DE, USA). Dielectric properties for the composite films were monitored according to the ASTM D150 on a TH 2819A precision LCR meter (Tonghui Electronic Co., Ltd., Dongguan, China). Before testing, conductive silver paste was brushed to a specific area on both sides of the samples to form a plate capacitor. The breakdown strength for PEN-based composite films was tested by a dc dielectric withstand voltage tester (catic era instrument equipment Co., Ltd., Beijing, China) in an oil bath. The applied voltage began at $40 \mathrm{~V}$ and increased at approximately $0.1 \mathrm{KV} / \mathrm{s}$ until the breakdown failure of a sudden current increase. The reported values were calculated as average values by five samples for each film.

\section{Results and Discussion}

\subsection{Characterizations of $\mathrm{F}-\mathrm{BaTiO}_{3}$ Particles}

The chemical composition and morphology of $\mathrm{F}_{-} \mathrm{BaTiO}_{3}$ particles were characterized by FTIR, TEM and XRD, respectively. Firstly, the surface modifying of $\mathrm{BaTiO}_{3}$ particles was verified by FTIR. As shown in Figure 3, a strong absorption peak appeared at $567 \mathrm{~cm}^{-1}$, which corresponds to the Ti-O vibration. Compared to pristine $\mathrm{BaTiO}_{3}$, two new absorption bands appeared at $1460 \mathrm{~cm}^{-1}$ and $1500 \mathrm{~cm}^{-1}$ in $\mathrm{F}_{-} \mathrm{BaTiO}_{3}$ belongs to the skeleton vibration of benzene rings in PEN-COOH. Moreover, the characteristic absorption peaks at 1022 and $1245 \mathrm{~cm}^{-1}$ belong to the symmetric and asymmetric stretching vibrations of aryl ether, respectively. In addition, the new absorption band at $2231 \mathrm{~cm}^{-1}$ in $\mathrm{F}_{-} \mathrm{BaTiO}_{3}$ is mainly attributed to the symmetrical stretching vibration of nitrile groups $(-\mathrm{CN})$. These results indicated the existence of $\mathrm{PEN}-\mathrm{COOH}$ in $\mathrm{F}_{-} \mathrm{BaTiO}_{3}$ particles. It is worth noting that the peak at $1712 \mathrm{~cm}^{-1}$ belonging to carboxyl groups $(-\mathrm{COOH})$ in $\mathrm{PEN}-\mathrm{COOH}$ is not observed in 
the $\mathrm{F}_{-}-\mathrm{BaTiO}_{3}$ particles. However, the new absorption bands at 1400 and $1633 \mathrm{~cm}^{-1}$ in $\mathrm{F}-\mathrm{BaTiO}_{3}$ are mainly attributed to the symmetric and asymmetric stretching vibrations of carbonyl groups $(\mathrm{C}=\mathrm{O})$, respectively. The latter suggested the successful chemical grafting of $\mathrm{PEN}-\mathrm{COOH}$ onto the surfaces of $\mathrm{BaTiO}_{3}$ particles [24].

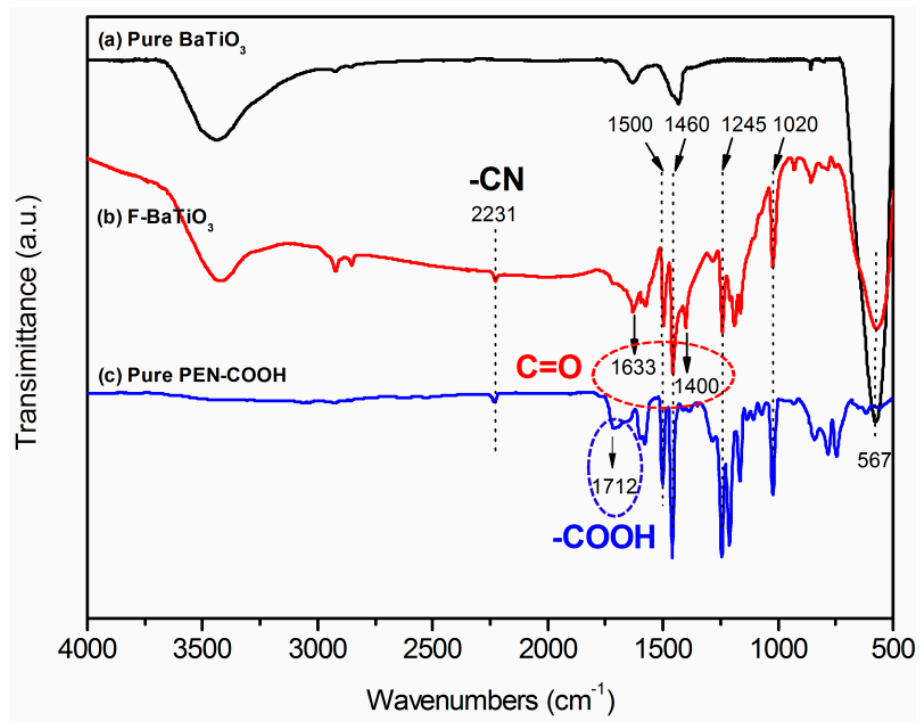

Figure 3. FTIR spectra of: (a) pure $\mathrm{BaTiO}_{3}$; (b) $\mathrm{F}-\mathrm{BaTiO}_{3}$; and (c) pure $\mathrm{PEN}-\mathrm{COOH}$.

TEM scanning is the visualized observation for the coating structure of $\mathrm{PEN}-\mathrm{COOH}$ around $\mathrm{BaTiO}_{3}$ particles. Figure 4a depicts a distinct contrast between PEN-COOH shell and $\mathrm{BaTiO}_{3}$ core. It can be clearly seen that the outermost light-colored layer belongs to the PEN-COOH layer, which grafted on the surface of $\mathrm{BaTiO}_{3}$ particles with a uniform thickness of 4-8 nm. The XRD spectra of pristine $\mathrm{BaTiO}_{3}$ and $\mathrm{F}-\mathrm{BaTiO}_{3}$ particles are shown in Figure $4 \mathrm{~b}$. These diffraction peaks at $2 \theta=22.2^{\circ}$, $31.6^{\circ}, 38.9^{\circ}, 45.3^{\circ}, 50.9,56.3^{\circ}, 65.9^{\circ}, 70.4^{\circ}$ and $74.8^{\circ}$ are clearly observed, which can be indexed to the pristine $\mathrm{BaTiO}_{3}$ crystal plane of (100), (110), (111), (200), (210), (211), (220), (221) and (310), respectively. Obviously, all of the characteristic diffraction peaks of $\mathrm{F}-\mathrm{BaTiO}_{3}$ matched well with the curve of pristine $\mathrm{BaTiO}_{3}$, which is well consistent with the standard cards (JCPDS 31-0174) [25]. Moreover, for these surface grafted $\mathrm{F}-\mathrm{BaTiO}_{3}$ particles, superfluous peaks cannot be detected, indicating the well-organized cubic crystal form [26].
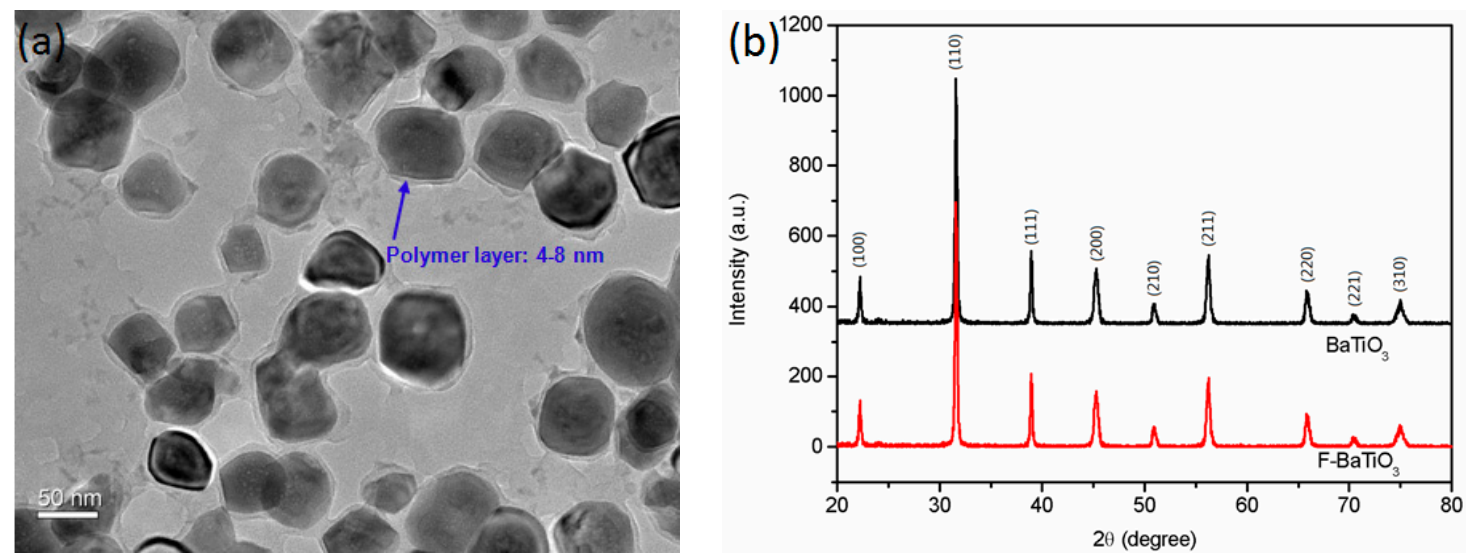

Figure 4. (a) TEM images of $\mathrm{F}-\mathrm{BaTiO}_{3}$ particles; and (b) $\mathrm{XRD}$ spectra of pristine $\mathrm{BaTiO}_{3}$ and $\mathrm{F}_{-\mathrm{BaTiO}}$ particles. 


\subsection{Chemical Structure and Morphology of CPEN Composite Films}

The chemical structure of the PEN-ph and CPEN films was characterized by FTIR. As shown in Figure 5, it is observed that three absorption bands appear at $1594 \mathrm{~cm}^{-1}, 1500 \mathrm{~cm}^{-1}$ and $1460 \mathrm{~cm}^{-1}$, which are attributed to skeleton vibration of benzene rings. The absorption band at $1245 \mathrm{~cm}^{-1}$ is clearly observed, which belonged to the absorption peak of aryl ether. The characteristic band at $2230 \mathrm{~cm}^{-1}$ is coming from the absorption peak of cyano groups $(-\mathrm{CN})$. A comparison with the PEN-ph film appeared some new absorption peaks in CPEN film, meaning that the formation of cross-linked network structure of the CPEN resin. Apparently, the absorption peak at $2231 \mathrm{~cm}^{-1}$ gradually weakened with curing treatment. However, the new absorption bands at 1721 and $1380 \mathrm{~cm}^{-1}$ are clearly observed in CPEN film, which are assigned to the characteristic peak of indole ring and triazine ring [27], respectively. In addition, the peak at $955 \mathrm{~cm}^{-1}$ belongs to the in-plane bending vibration of $\mathrm{C}-\mathrm{N}$. These results further indicated that the cross-linking of CPEN was successfully realized at high temperature, and formed the cross-linked network structure in the CPEN matrix. Furthermore, the cross-linking degree of the fragmented pure PEN-ph and CPEN film were measured through Soxhlet extraction, using NMP as solvent. Samples were refluxed in NMP for $48 \mathrm{~h}$. It can be clearly observed that the fragmented PEN-ph film is completely dissolved in NMP. However, the fragmented CPEN film almost maintains a constant weight. The results indicated that the cross-linking degree of CPEN film is almost $100 \%$, thus improving the thermal stability of the CPEN film.

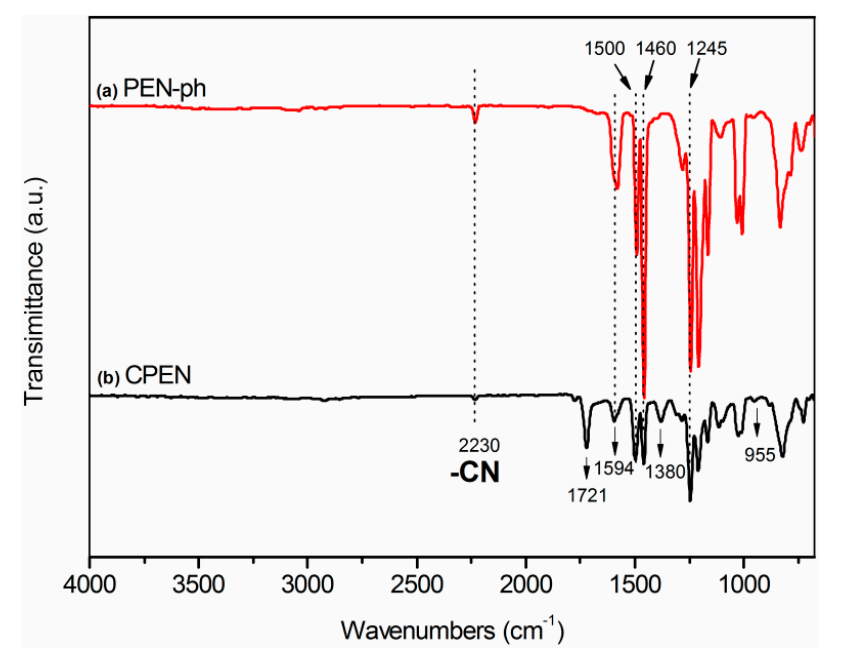

Figure 5. FTIR spectra of: (a) PEN-ph; and (b) CPEN films.

The cross-section morphologies of CPEN composite films were investigated through SEM, as presented in Figure 6. After the post curing, the pure CPEN film becomes rigid compared with pure PEN-ph film. In addition, the pure CPEN film showed homogeneous and smooth fracture morphology (Figure 6a), suggesting typical brittle fractures of a thermosetting material. Besides, the dispersibility and interfacial compatibility of fillers in CPEN matrix can also be clearly observed from the cross-sectional SEM images. As shown in Figure $6 \mathrm{~b}$, the $20 \mathrm{wt} \% \mathrm{~F}^{-\mathrm{BaTiO}_{3}}$ filled composite film displays relatively rough surface morphologies with wave-like structures. Importantly, there is almost no $\mathrm{BaTiO}_{3}$ particle agglomeration and the $\mathrm{F}-\mathrm{BaTiO}_{3}$ particles are perfectly embedded in CPEN matrix. Besides, the enlarged detail of Figure $6 \mathrm{~b}$ (see Figure $6 \mathrm{c}$ ) shows that the interface between $\mathrm{F}_{-} \mathrm{BaTiO}_{3}$ particles and $\mathrm{CPEN}$ matrix is indistinguishable, indicating improved interactions between the two phases through the PEN-COOH grafting. However, the comparison with $\mathrm{F}_{-} \mathrm{BaTiO}_{3}$ filled composite film revealed that the phase interface between pristine $\mathrm{BaTiO}_{3}$ particles and CPEN matrix is fairly distinct, indicating a worse interfacial compatibility in this case (as seen from Figure 6d). These results can be attributed to the benefit of coating layer (PEN-COOH) on the surface of $\mathrm{BaTiO}_{3}$ particles, improving the dispersal uniformity of $\mathrm{BaTiO}_{3}$ particles and promoting adhesion 
among $\mathrm{BaTiO}_{3}$ and $\mathrm{PEN}$-ph matrix. Therefore, it can be predicted that the $\mathrm{CPEN} / \mathrm{F}-\mathrm{BaTiO}_{3} \mathrm{composite}$ films will present excellent comprehensive performance, which is extremely important for expanding its practical application.
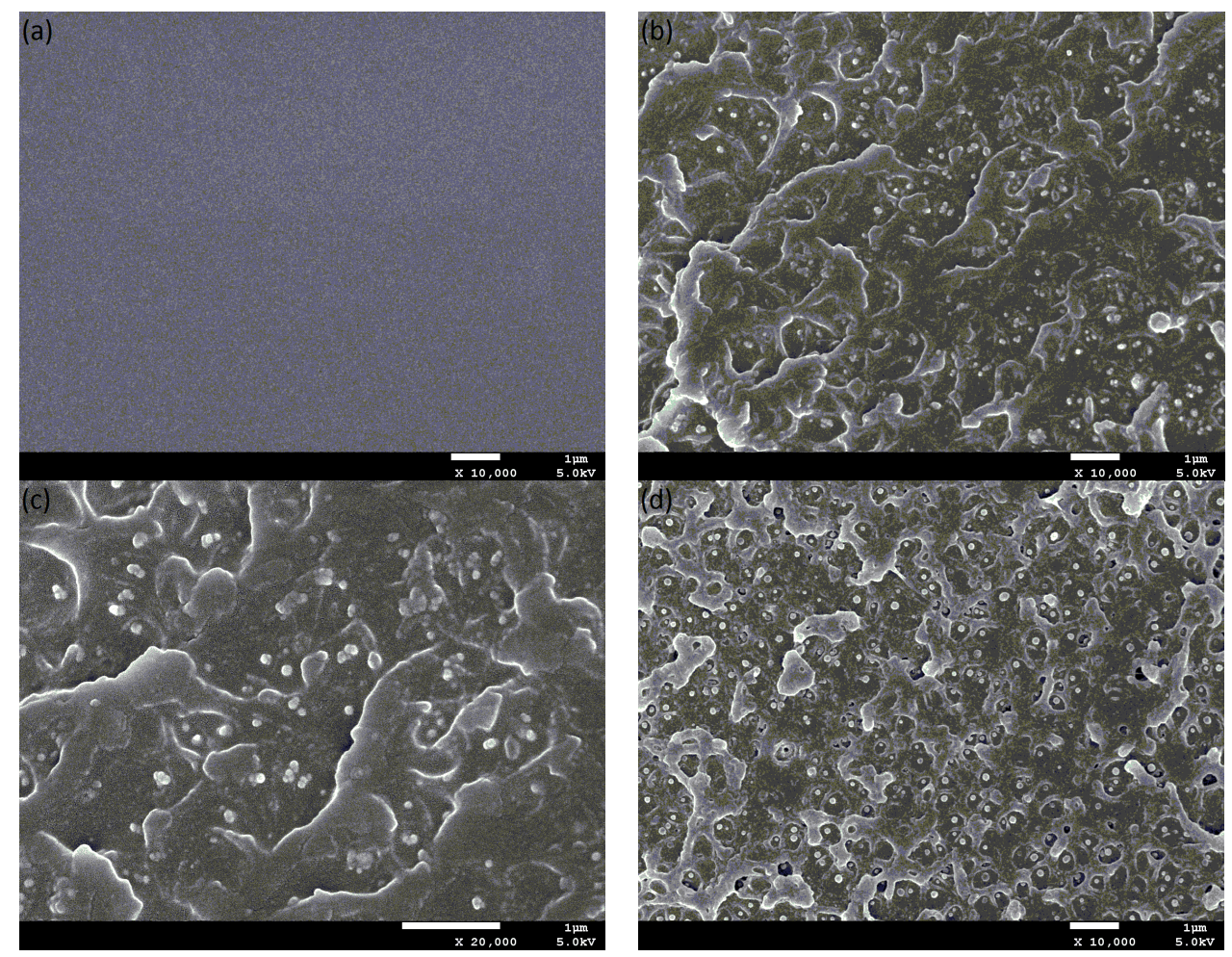

Figure 6. Cross-sectional SEM images of CPEN composite films with different $\mathrm{F}-\mathrm{BaTiO}_{3}$ loading: (a) $0 \mathrm{wt} \%$; and (b) $20 \mathrm{wt} \%$; (c) enlarged details of (b); and (d) CPEN composite films with $20 \mathrm{wt} \%$ pristine $\mathrm{BaTiO}_{3}$ loading.

\subsection{Mechanical Properties of CPEN Composite Films}

As a high-performance thermoplastic polymer, PEN-ph possesses outstanding properties including high thermal stability, excellent mechanical properties as well as chemical resistance [28-30]. Most importantly, the phthalonitrile is capped at the ends of PEN-ph can form cross-linked three-dimensional network structure at high temperature, thus further improving above-mentioned properties. The tensile strength and tensile modulus of pure PEN-ph film are $81 \mathrm{MPa}$ and 2155 $\mathrm{MPa}$, respectively [31]. After chemical cross-linking, the stress-strain curves of the CPEN/F-BaTiO composite films are shown in Figure 7a. It can be seen that the increase inF-BaTiO ${ }_{3}$ loading content raises Young's modulus of all $\mathrm{CPEN} / \mathrm{F}-\mathrm{BaTiO}_{3}$ composite films. That is attributed to the contribution of ceramic particles on the modulus of all CPEN composite films. With increasing fillers content, the tensile strength decreases gradually but still higher than that of pure PEN-ph film. Comparing with the pure PEN-ph film, the tensile strength of P-0, P-1, P-2, P-3 and P-4 increased by $25 \%$, $33 \%, 54 \%, 63 \%$ and $67 \%$, respectively. The effective increase of the mechanical properties results from the increasing of cross-linking density to some extent. Besides, the elongation at break of the $\mathrm{CPEN} / \mathrm{F}-\mathrm{BaTiO}_{3}$ composite films continuously decreases with the increasing $\mathrm{F}-\mathrm{BaTiO}_{3}$ loading content, declining to $2.7 \%$ from $11.1 \%$. This similar phenomenon has widely been observed in many reported polymer/inorganic composite systems [32]. Figure $7 \mathrm{~b}$ shows the chemical resistance of the composite films to a strong dissolving solvent, where $\mathrm{PEN}-\mathrm{ph} / \mathrm{F}-\mathrm{BaTiO}_{3}$ and $\mathrm{CPEN} / \mathrm{F}-\mathrm{BaTiO}_{3}$ composite films with $20 \mathrm{wt} \%$ fillers loading content were soaked in NMP and maintained for $4 \mathrm{~h}$ at $60{ }^{\circ} \mathrm{C}$ in an ultrasonic water bath. It is obviously observed that the $\mathrm{PEN}-\mathrm{ph} / \mathrm{F}-\mathrm{BaTiO}_{3}$ film was completely dissolved and formed a uniform dispersion solution (Figure 7b, left). Particularly, the CPEN/F-BaTiO 3 
composite film actually maintained its original shape during the process (Figure $7 \mathrm{~b}$, right), which can be attributed to the chemically cross-linked PEN-ph matrix.
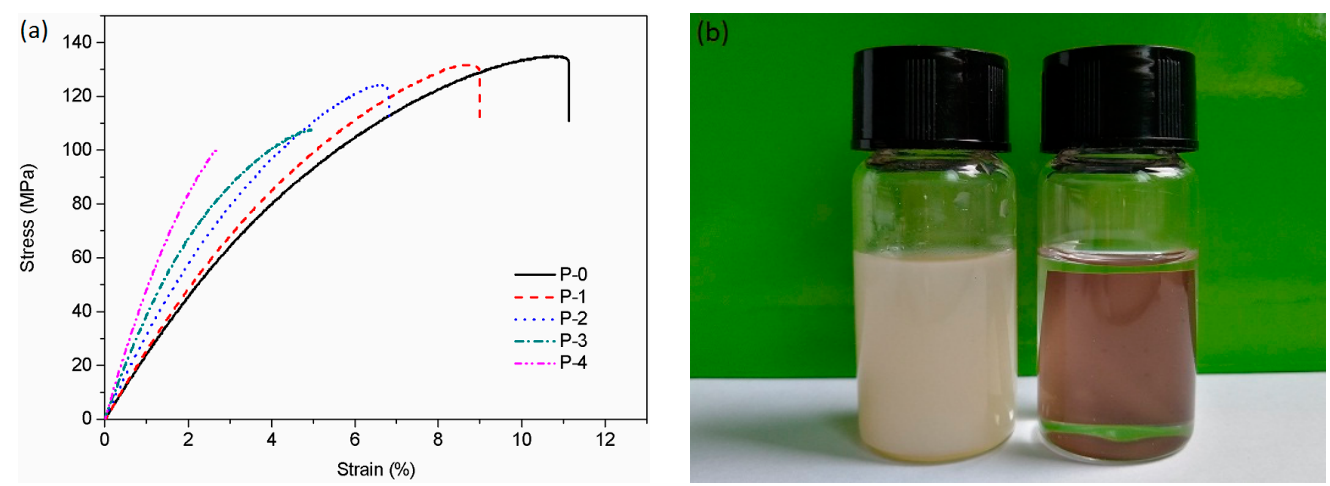

Figure 7. (a) The stress-strain curves of the $\mathrm{CPEN} / \mathrm{F}-\mathrm{BaTiO}_{3}$ composite films; and (b) digital figures of composite films with same filler loadings in NMP: uncross-linked (left); and cross-linked (right).

\subsection{Dynamic Mechanical Properties of CPEN Composite Films}

The thermal properties of the CPEN composite films were investigated by means of dynamic mechanical analysis (DMA) and their DMA curves are shown in Figure 8. As can be seen, the storage modulus increases with the increasing of $\mathrm{F}^{-\mathrm{BaTiO}_{3}}$ loading content (see Figure 8a), which is attributed to the contribution of rigid particles $\left(\mathrm{BaTiO}_{3}\right)$ on the modulus of all samples. Furthermore, the storage modulus gradually decreases as the temperature rises up to the onset of the glass relaxation, and then decreases abruptly during the glass relaxation, as expected. Importantly, it can be seen that all CPEN composite films present a damping peak for Tan delta in the range from $350{ }^{\circ} \mathrm{C}$ to $380{ }^{\circ} \mathrm{C}$ (as seen in Figure $8 \mathbf{b}$ ), which corresponds to the glass transition temperature $\left(T_{\mathrm{g}}\right)$ of the CPEN composite films. As can be seen, the $T_{\mathrm{g}}$ of the P-0 film is around $355^{\circ} \mathrm{C}$, which is higher than that of PEN-ph film $\left(165^{\circ} \mathrm{C}\right)$ [31]. In comparison with P-0 film, the $T_{\mathrm{g}}$ of P-1, P-2, P-3 and P-4 films are, respectively, increased by $6^{\circ} \mathrm{C}, 13{ }^{\circ} \mathrm{C}, 18^{\circ} \mathrm{C}$ and $20^{\circ} \mathrm{C}$. These results demonstrated that the $T_{\mathrm{g}}$ gradually increase as the degree of cross-linking reaction and $\mathrm{F}-\mathrm{BaTiO}_{3}$ loading content increases. This may be attributed to three reasons as follows. Firstly, the film is self-cross-linked by the phthalonitrile groups capped at the ends of linear PEN-ph, which is the primary contributor of $T_{\mathrm{g}} \mathrm{s}$ increase. Secondly, it may be due to the improved dispersibility of filler and the strong physical entanglements of macromolecular chains between the functional intermediate PEN-COOH and PEN-ph matrix can reduce free volume and segmental mobility, thereby improving the $T_{\mathrm{g}}$. Thirdly, both PEN-COOH and PEN-ph have pendant nitrile groups $(-\mathrm{CN})$, which can also form network structure between PEN-COOH and PEN-ph through chemical cross-linking.
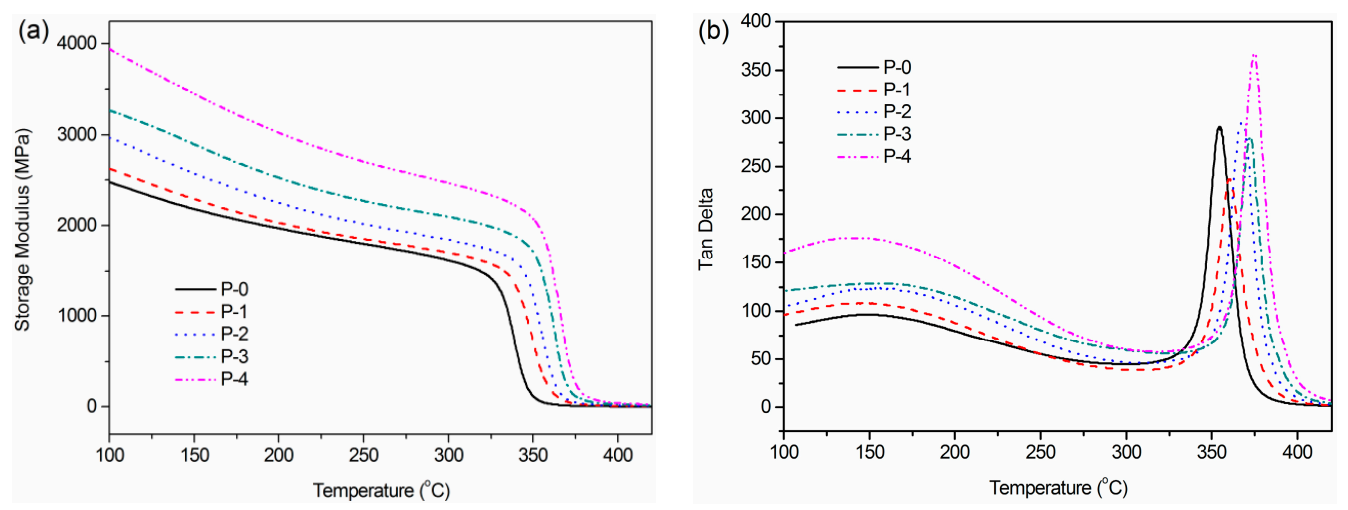

Figure 8. DMA measurement for $\mathrm{CPEN} / \mathrm{F}-\mathrm{BaTiO}_{3}$ composite films with different $\mathrm{F}-\mathrm{BaTiO}$ loading: (a) the storage modulus; and (b) tan $\delta$ of composite films versus temperature. 


\subsection{Dielectric Properties of CPEN Composite Films}

The dielectric constant and loss tangent of $\mathrm{CPEN} / \mathrm{F}-\mathrm{BaTiO}_{3} \mathrm{Composite}$ films were measured at room temperature as a function of frequency (Figure 9). The introduction of high-kF-BaTiO $\mathrm{Barticles}_{3}$ was the reason for the elevated dielectric constant, which has been well researched and finely predicted by using a series of parallel models [33,34]. For P-0 film, the dielectric constant (4.2) and loss tangent (0.011) are almost the same in the measured frequency range of $100 \mathrm{~Hz}-200 \mathrm{kHz}$. The dielectric constant of both composite films decreased slightly as a function of frequency, which is attributed to the effect of the polarization relaxation [35]. For P-1 composite film, the dielectric constant reached 6.4 at $1 \mathrm{kHz}$ with an increment of $52 \%$ in comparison with that of $\mathrm{P}-0$, which can be attributed to the introduction of high- $\mathrm{kBaTiO}_{3}$ particles. As shown in Figure 9a, it can be seen that the increase in $\mathrm{F}_{-} \mathrm{BaTiO}_{3}$ loading content raised nonlinearly the dielectric constant of all CPEN composite films. Specifically, the dielectric constant of P-4 composite film shows an about 4-fold increase at $1 \mathrm{kHz}$ (up to 15.2 from 4.2 of P-0). Similar tendency can also be observed for the dielectric loss of the CPEN/F-BaTiO 3 composite films (see from Figure 9b). Although the dielectric loss of $\mathrm{CPEN} / \mathrm{F}-\mathrm{BaTiO}_{3} \mathrm{composite}$ films also increased with increasing content of $\mathrm{F}_{-}-\mathrm{BaTiO}_{3}$, all of the $\mathrm{CPEN} / \mathrm{F}-\mathrm{BaTiO}_{3}$ composite films show relatively low dielectric loss, which is as low as 0.023 for P-4 at $1 \mathrm{kHz}$. Importantly, it is much lower than the $\mathrm{F}_{-\mathrm{BaTiO}} / \mathrm{PEN}$ composite at the same content of fillers reported in the reported literature [10]. The result is because the $\mathrm{F}-\mathrm{BaTiO}_{3}$ particleshave good dispersibility and compatibility with the polymer matrix, which leads to a decrease of dielectric loss derived from interfacial polarization between inorganic and organic phases $[1,33]$.
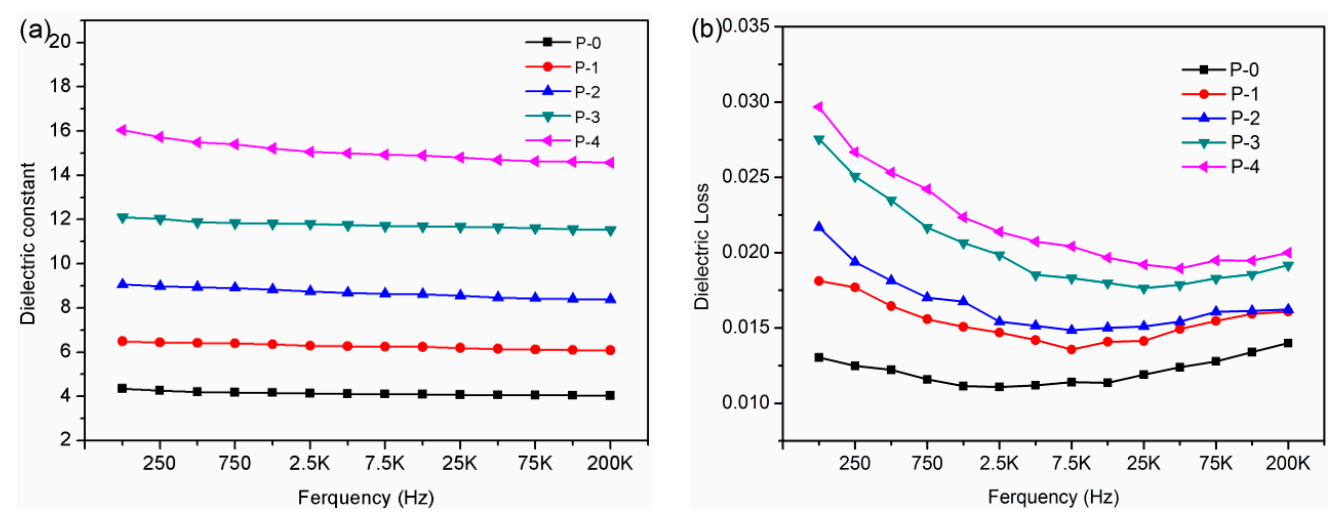

Figure 9. (a) Dielectric constant; and (b) loss tangent of $\mathrm{CPEN} / \mathrm{F}-\mathrm{BaTiO}_{3}$ composite films as a function of frequency.

\subsection{Electric Breakdown and Energy Storage Capacity of CPEN Composite Films}

As indicated in the equation $U=1 / 2 \cdot \varepsilon_{0} \cdot \varepsilon_{\mathrm{r}} \cdot\left(E_{\mathrm{b}}\right)^{2}$ (where $\varepsilon_{0}$ is the vacuum dielectric constant with the value of $8.85 \times 10^{-12} \mathrm{~F} / \mathrm{m}, \varepsilon_{\mathrm{r}}$ is the relative dielectric constant, and $E_{\mathrm{b}}$ is the dielectric breakdown strength), elevated breakdown strength of dielectric materials is rather important for achieving superior energy storage capacities. As can be seen from the above-mentioned equation, two variables $\left(\varepsilon_{\mathrm{r}}\right.$ and $E_{\mathrm{b}}$ ) together determine the value of energy density. For the practical application in capacitor field, high permittivity and excellent breakdown strength of the materials are necessary. As can be seen in Figure $10 \mathrm{a}$, the breakdown strength of the P-0 film is as high as $224 \mathrm{KV} / \mathrm{mm}$, and a further increase in $\mathrm{F}_{-\mathrm{BaTiO}}$ loading content led to a gradual decrease in $E_{\mathrm{b}}$. As expected, the dielectric constant of both composites increases with the increasing $\mathrm{F}_{-} \mathrm{BaTiO}_{3}$ loading, and the increment of dielectric constant rises nonlinearly. As the $\mathrm{F}_{-} \mathrm{BaTiO}_{3}$ content increases to $30 \mathrm{wt} \%$, the calculated results show that the P-3 composite film exhibits a maximum energy density of up to $1.73 \mathrm{~J} / \mathrm{cm}^{3}$, which is $90 \%$ superior than the values obtained with P-0 film $\left(0.91 \mathrm{~J} / \mathrm{cm}^{3}\right)$. This is the result of increase in dielectric constant and slight decrease in breakdown strength. With further increasing the $\mathrm{F}^{-\mathrm{BaTiO}_{3}}$ loading, although the dielectric constant still increases, the breakdown strength decreases dramatically, resulting in the decrease of 
energy storage density. The result is because high mass fraction of the $\mathrm{F}^{-\mathrm{BaTiO}_{3}}$ in the composite films may result in partial agglomeration of particles and increase in porosity, which could increase the uneven distribution of the electric field inside the composite films and weaken the breakdown strength $[7,11,36]$.
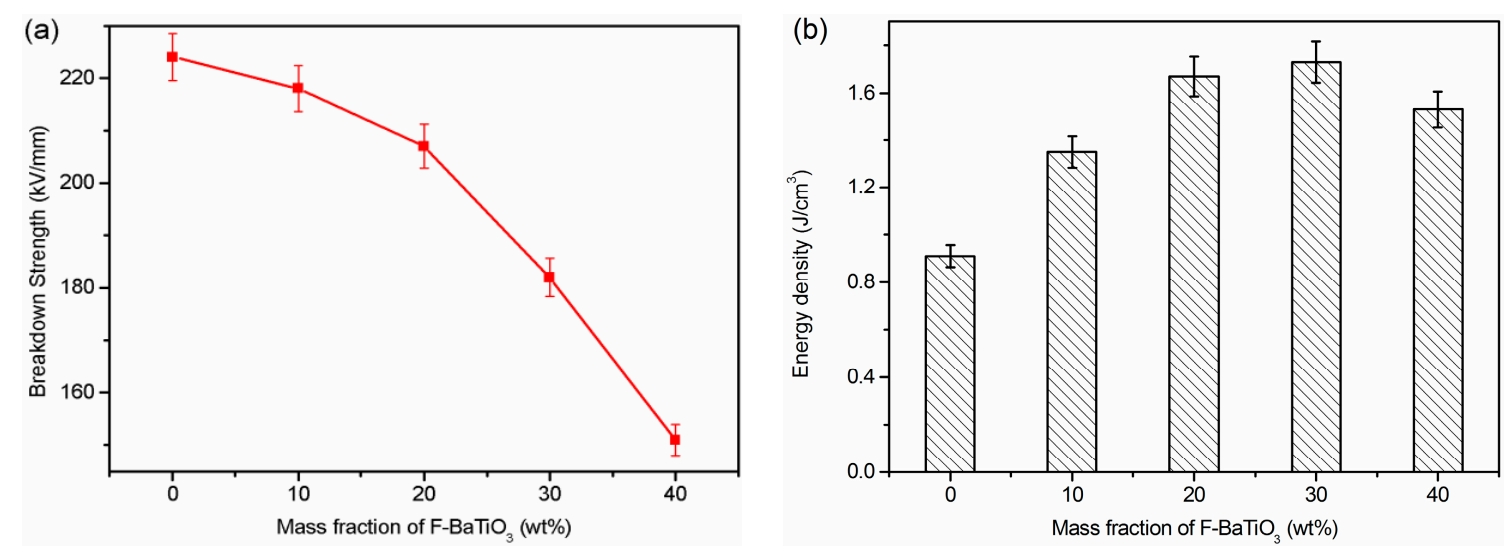

Figure 10. (a) The breakdown strength; and (b) energy density of the CPEN/F-BaTiO 3 composite films at room temperature.

\section{Conclusions}

Cross-linked polymer-based films as flexible dielectric materials that can be used at ultrahightemperature condition were prepared. $\mathrm{BaTiO}_{3}$ particles were firstly chemical modified with PEN-COOH to form the shielding layers on their surface. The $\mathrm{F}_{-} \mathrm{BaTiO}_{3}$ particles were characterized using FTIR, TEM and XRD. Then, the CPEN/F-BaTiO ${ }_{3}$ dielectric films with thickness of $\sim 60 \mu \mathrm{m}$ were fabricated by melt processing combined with post curing at high temperature. According to the results of DMA measurement, the $\mathrm{CPEN} / \mathrm{F}-\mathrm{BaTiO}_{3}$ composite films present ultra-high $T_{\mathrm{gs}}$ (higher than $355^{\circ} \mathrm{C}$ ). Due to the chemical cross-linking, the mechanical properties of $\mathrm{CPEN} / \mathrm{F}-\mathrm{BaTiO}_{3} \mathrm{composite}$ films were greatly enhanced. In addition, the composite films also show high breakdown strength, stable dielectric constant and low dielectric loss. As the mass fraction of $\mathrm{F}^{-\mathrm{BaTiO}_{3}}$ increases to $30 \mathrm{wt} \%$, the calculated results indicate that the P-3 composite film exhibits a maximum energy density of up to $1.73 \mathrm{~J} / \mathrm{cm}^{3}$, which is $90 \%$ better than the values obtained with P-0 film $\left(0.91 \mathrm{~J} / \mathrm{cm}^{3}\right)$. In consideration of these advantages, the $\mathrm{CPEN} / \mathrm{F}-\mathrm{BaTiO}_{3}$ composite film would be a promising candidate as the dielectric materials used in high-performance electronic devices.

Acknowledgments: The authors thank the Sichuan University of Science and Engineering Talent Introduction Project (No. 2016RCL35, No. 2015RC56), Material Corrosion and Protection Key Laboratory of Sichuan Province Open Fund Projects (2016CL16) and Key Science and Technology Planning Project of Zigong City (2017XC04).

Author Contributions: Zejun $\mathrm{Pu}$ and Xiaoyi Zheng designed and conducted the experiments, performed the data analysis, and wrote the manuscript. Yuhan Tian, Linqing Hu and Jiachun Zhong edited and revised manuscript. All authors approved the final version of the manuscript.

Conflicts of Interest: The authors declare no conflict of interest.

\section{References}

1. Li, C.; Tang, A.B.; Zou, Y.K.; Liu, X.B. Preparation and dielectric properties of polyarylene ether nitriles $/ \mathrm{TiO}_{2}$ nanocomposite film. Mater. Lett. 2005, 59, 59-63. [CrossRef]

2. Zhan, Y.Q.; Wan, X.Y.; He, J.S.; Yang, Q.B.; He, Y. Design of durable and efficient poly(arylene ether nitrile)/bioinspired polydopamine coated graphene oxide nanofibrous composite membrane for anionic dyes separation. Chem. Eng. J. 2018, 333, 132-145. [CrossRef] 
3. You, Y.; Du, X.; Mao, H.; Tang, X.H.; Wei, R.B.; Liu, X.B. Synergistic enhancement of mechanical, crystalline and dielectric properties of polyarylene ether nitrile-based nanocomposites by unidirectional hot stretching-quenching. Polym. Int. 2017, 66, 1151-1158. [CrossRef]

4. Huang, X.; Pu, Z.J.; Feng, M.N.; Tong, L.F.; Liu, X.B. BaTiO $@$ @ MWCNTs core/shell nanotubes embedded PEN nanocomposite films with high thermal stability and high permittivity. Mater. Lett. 2013, 96, 139-142. [CrossRef]

5. Tang, H.L.; Huang, X.; Yang, X.L.; Yang, J.; Zhao, R.; Liu, X.B. An effective approach to enhance temperature independence of dielectric properties for polyarylene ether nitrile films. Mater. Lett. 2012, 75, 218-220. [CrossRef]

6. Wei, R.B.; Li, K.; Ma, J.Y.; Zhang, H.X.; Liu, X.B. Improving dielectric properties of polyarylene ether nitrile with conducting polyaniline. J. Mater. Sci. Mater. Electron. 2016, 27, 9565-9571. [CrossRef]

7. Pu, Z.J.; Tong, L.F.; Feng, M.N.; Jia, K.; Liu, X.B. Influence of hyperbranched copper phthalocyanine grafted carbon nanotubes on the dielectric and rheological properties of polyarylene ether nitriles. RSC Adv. 2015, 5, 72028-72036. [CrossRef]

8. Zhan, Y.Q.; Yang, X.L.; Guo, H.; Yang, J.; Meng, F.B.; Liu, X.B. Cross-linkable nitrile functionalized graphene oxide/poly (arylene ether nitrile) nanocomposite films with high mechanical strength and thermal stability. J. Mater. Chem. 2012, 22, 5602-5608. [CrossRef]

9. Huang, X.; Wang, K.; Jia, K.; Liu, X.B. Polymer-based composites with improved energy density and dielectric constants by monoaxial hot-stretching for organic film capacitor applications. RSC Adv. 2015, 5, 51975-51982. [CrossRef]

10. Tang, H.L.; Wang, P.; Zheng, P.L.; Liu, X.B. Core-shell structured BaTiO3 @polymer hybrid nanofiller for poly(arylene ether nitrile) nanocomposites with enhanced dielectric properties and high thermal stability. Compos. Sci. Technol. 2016, 123, 134-142. [CrossRef]

11. Xie, Y.C.; Yu, Y.Y.; Feng, Y.F.; Jiang, W.R.; Zhang, Z.C. Fabrication of stretchable nanocomposites with high energy density and low loss from cross-linked PVDF filled with poly (dopamine) encapsulated $\mathrm{BaTiO}_{3}$. ACS Appl. Mater. Interface 2017, 9, 2995-3005. [CrossRef] [PubMed]

12. Yang, R.Q.; Wei, R.B.; Li, K.; Tong, L.F.; Jia, K.; Liu, X.B. Crosslinked polyarylene ether nitrile film as flexible dielectric materials with ultrahigh thermal stability. Sci. Rep. 2016, 6, 36434. [CrossRef] [PubMed]

13. Xie, L.Y.; Huang, X.Y.; Wu, C.; Jiang, P.K. Core-shell structured poly(methyl methacrylate) $/ \mathrm{BaTiO}_{3}$ nanocomposites prepared by in situ atom transfer radical polymerization: A route to high dielectric constant materials with the inherent low loss of the base polymer. J. Mater. Chem. 2011, 21, 5897-5906. [CrossRef]

14. Yang, K.; Huang, X.Y.; Huang, Y.H.; Xie, L.Y.; Jiang, P.K. Fluoro-polymer@BaTiO 3 hybrid nanoparticles prepared via RAFT polymerization: Toward ferroelectric polymer nanocomposites with high dielectric constant and low dielectric loss for energy storage application. Chem. Mater. 2013, 25, 2327-2338. [CrossRef]

15. Li, Y.H.; Yuan, J.J.; Xue, J.; Cai, F.Y.; Chen, F.; Fu, Q. Towards suppressing loss tangent: Effect of polydopamine coating layers on dielectric properties of core-shell barium titanate filled polyvinylidene fluoride composites. Compos. Sci. Technol. 2015, 118, 198-206. [CrossRef]

16. Zhang, G.Q.; Brannum, D.; Dong, D.X.; Tang, L.X.; Allahyarov, E.; Tang, S.; Kodweis, K.; Lee, J.K.; Zhu, L. Interfacial polarization-induced loss mechanisms in polypropylene $/ \mathrm{BaTiO}_{3}$ nanocomposite dielectrics. Chem. Mater. 2016, 28, 4646-4660. [CrossRef]

17. Wan, Y.J.; Zhu, P.L.; Yu, S.H.; Yang, W.H.; Sun, R.; Wong, C.P.; Liao, W.H. Barium titanate coated and thermally reduced graphene oxide towards high dielectric constant and low loss of polymeric composites. Compos. Sci. Technol. 2017, 141, 48-55. [CrossRef]

18. Tang, H.L.; Tong, L.F.; Wei, J.J.; Guo, H.Y.; Liu, X.B. An effective and controllable approach to derive polymer corona on oxide nanoparticles to enhance their compatibility in polymeric nanocomposites. Mater. Lett. 2013, 93, 285-288. [CrossRef]

19. Zou, Y.K.; Yang, J.; Zhan, Y.Q.; Yang, X.L.; Zhong, J.C.; Zhao, R.; Liu, X.B. Effect of curing behaviors on the properties of poly (arylene ether nitrile) end-capped with phthalonitrile. J. Appl. Polym. Sci. 2012, 125, 3829-3835. [CrossRef]

20. Tang, H.L.; Pu, Z.J.; Huang, X.; Wei, J.J.; Liu, X.B.; Lin, Z.Q. Novel blue-emitting carboxyl functionalized poly(arylene ether nitrile)s with excellent thermal and mechanical properties. Polym. Chem. 2014, 11, 3673-3679. [CrossRef] 
21. Yang, R.Q.; Li, K.; Tong, L.F.; Jia, K.; Liu, X.B. The relationship between processing and performances of polyarylene ether nitriles terminated with phthalonitrile/trifunctional phthalonitrile composites. J. Polym. Res. 2015, 22, 1-9. [CrossRef]

22. Snow, A.W.; Griffith, J.R.; Marullo, N.P. Syntheses and characterization of heteroatom-bridged metal-free phthalocyanine network polymers and model compounds. Macromolecules 1984, 17, 1614-1624. [CrossRef]

23. Tong, L.F.; Pu, Z.J.; Huang, X.; Chen, Z.R.; Yang, X.L.; Liu, X.B. Crosslinking behavior of polyarylene ether nitrile terminated with phthalonitrile (PEN-t-Ph)/1,3,5-Tri-(3,4-dicyanophenoxy) benzene (TPh) system and its enhanced thermal stability. J. Appl. Polym. Sci. 2013, 130, 1363-1368. [CrossRef]

24. Shi, X.; Zhu, G.S.; Wang, X.H.; Li, G.H.; Fang, Q.R.; Zhao, X.J.; Wu, G.; Tian, G.; Xue, M.; Wang, R.W.; et al. Polymeric frameworks constructed from a metal-organic coordination compound, in 1-D and 2-D systems: synthesis, crystal structures, and fluorescent properties. Cryst. Growth Des. 2015, 5, 341-346. [CrossRef]

25. Suchanicz, J.; Swierczek, K.; Nogas-Cwikiel, E.; Konieczny, K.; Sitko, D. PbMg ${ }_{1 / 3} \mathrm{Nb}_{2 / 3} \mathrm{O}_{3}$-doping effects on structural, thermal, Raman, dielectric and ferroelectric properties of $\mathrm{BaTiO}_{3}$ ceramics. J. Eur. Ceram. Soc. 2015, 35, 1777-1783. [CrossRef]

26. Cui, Y.F.; Briscoe, J.; Dunn, S. An investigation into the effect of ferroelectricity of $\mathrm{BaTiO}_{3}$ on the photocatalytic activity in dye decolourisation. Adv. Sci. Technol. 2014, 93, 190-195. [CrossRef]

27. Tong, L.F.; Jia, K.; Liu, X.B. Phthalonitrile end-capped polyarylene ether nitrile: Crystals embedded in matrix through crosslinking reaction. Polym. Int. 2015, 64, 1361-1365. [CrossRef]

28. Tong, L.F.; Jia, K.; Liu, X.B. Novel phthalonitrile-terminated polyarylene ether nitrile with high glass transition temperature and enhanced thermal stability. Mater. Lett. 2014, 128, 267-270. [CrossRef]

29. Tong, L.F.; Zheng, P.L.; Tang, H.L.; Jia, K.; Liu, X.B. Novel high-temperature- resistant single-polymer composites based on self-reinforced phthalonitrile end-capped polyarylene ether nitrile. Mater. Lett. 2015, 159, 337-340. [CrossRef]

30. Yang, R.Q.; Xiao, Q.; You, Y.; Wei, R.B.; Liu, X.B. In situ catalyzed and reinforced high-temperature flexible crosslinked ZnO nano-whisker/polyarylene ether nitriles composite dielectric films. Polym. Compos. 2016. [CrossRef]

31. Wei, R.B.; Wang, J.L.; Zhang, H.X.; Han, W.H.; Liu, X.B. Crosslinked polyarylene ether nitrile interpenetrating with zinc ion bridged graphene sheet and carbon nanotube network. Polymers 2017, 9, 342. [CrossRef]

32. Pu, Z.J.; Tang, H.L.; Huang, X.; Yang, J.; Zhan, Y.Q.; Zhao, R.; Liu, X.B. Effect of surface functionalization of $\mathrm{SiO}_{2}$ particles on the interfacial and mechanical properties of PEN composite films. Colloid Surf. A 2012, 415, 125-133. [CrossRef]

33. Huang, X.Y.; Jiang, P.K. Core-shell structured high-k polymer nanocomposites for energy storage and dielectric applications. Adv. Mater. 2015, 27, 546-554. [CrossRef] [PubMed]

34. Yoon, D.H.; Zhang, J.; Lee, B.I. Dielectric constant and mixing model of $\mathrm{BaTiO}_{3}$ composite thick films. Mater. Res. Bull. 2003, 38, 765-772. [CrossRef]

35. Deligöz, H.; Yalcinyuvaa, T.; Özgümüsa, S.; Yildirimb, S. Preparation, characterization and dielectric properties of 4, 4-diphenylmethane diisocyanate (MDI) based cross-linked polyimide films. Eur. Polym. J. 2006, 42, 1370-1377. [CrossRef]

36. Wang, Y.F.; Cui, J.; Yuan, Q.B.; Niu, Y.J.; Bai, Y.Y.; Wang, H. Significantly enhanced breakdown strength and energy density in sandwich-structured barium titanate/poly(vinylidene fluoride) nanocomposites. Adv. Mater. 2015, 27, 6658-6663. [CrossRef] [PubMed]

(C) 2017 by the authors. Licensee MDPI, Basel, Switzerland. This article is an open access article distributed under the terms and conditions of the Creative Commons Attribution (CC BY) license (http:/ / creativecommons.org/licenses/by/4.0/). 